\title{
Fundaciones y destrucciones: Pablo Neruda y Nicanor Parra*
}

Neruda y Parra, el poeta y el antipoeta, las dos estaturas más altas dentro de la poesía chilena. El "anti" de Parra no pone entre los dos un enconado abismo personal. No son fieros enemigos. Se visitan y a veces, nos cuenta Parra, intercambian regalos, "objetos prácticos y simbólicos: un Whitman contra un López Velarde, una cerámica de Quinchamalí contra un poncho araucano, un reloj de bolsillo contra un jardín de siemprevivas, mariposas, etc." 1

Sus relaciones parecen obedecer a una clave con cuyo ocultamiento ellos, que están en el secreto, disfrutan entre serios y divertidos. Saben bien lo que los separa; pero la misma conciencia que capta las diferencias acepta también su legitimidad, el derecho que le asiste al otro sobre lo que ha conquistado: son dos señores que no se han reunido para disputarse méritos a zarpazos, sino para medirse en el respeto desde juris. dicciones opuestas. Para expresar su reconocimiento, Parra elige el camino indirecto de la paradoja: "Hay dos maneras de refutar a Neruda: una es no leyéndolo, la otra es leyéndolo de mala fe. Yo he practicado ambas, pero ninguna me dio resultado". ${ }^{2}$ Neruda prefiere la vía directa y metafórica: "entre todos los poetas del sur de América, poetas extrema-

* Este trabajo es un capítulo de un libro, en preparación, dedicado al estudio de la poesía de Nicanor Parra.

Las citas de poemas de Parra han sido tomadas de Obra gruesa. (Santiago de Chile, Editorial Universitaria, 1969), libro que contiene la mayor parte de la producción (no se incluye Cancionero sin nombre ni Artefactos). Los poemas sueltos aparecen reunidos en este libro bajo el título de Otros poemas, y algunos de los que hemos citado en el trabajo están referidos a esa sección.

1 Pablo Neruda y Nicanor Parra, Discursos. Santiago de Chile, Editorial Nascimento, 1962. Parra, "Discurso de Bienvenida en Honor de Pablo Neruda", p. 10.

2 Discurso citado, p. 9. 
damente terrestres, la poesía versátil de Nicanor Parra se destaca por su follaje singular y sus fuertes raíces. Este gran trovador puede de un solo vuelo cruzar los más sombríos misterios o redondear como una vasija el canto con las más sutiles líneas de la gracia". ${ }^{3}$

Si reconstituyéramos la génesis histórica de la poesía de Parra, no cabe duda que ahí, en el origen, hallaríamos una gran presencia: la poesía de Neruda. Sin ésta, aquélla no existiria o no sería lo que es. Eliminemos de inmediato dos posibles conclusiones falsas: la primera, deducir que Neruda ha "influido" en Parra, como un maestro en un discípulo obediente; la segunda, pensar que la misión de Parra ha sido la de "negar" a Neruda y que en la negación agota su significado. No, nosotros aludimos a algo muy distinto, más dialéctico. Hacia 1938 el ciclo estupendo de los poetas anteriores, Huidobro, Neruda, de Rokha, se encontraba al borde de su cierre. Los jóvenes de entonces estaban condenados a perderse si fracasaban en la tarea (terrible tarea) de liquidar ese ciclo resolviéndolo en otro que fuera su natural y lógica conseciencia.

Ninguna creación, poética o de pensamiento, se consuma en el vacío sino en la discordia de las generaciones, en el antagonismo que una vigencia plantea a quienes deben superarla. Por eso, decía Ortega, "todo pensar es un pensar contra, manifiéstese o no en el decir. Siempre nuestro pensar creador se plasma en oposición a otro pensar que hay a la vista y que nos parece erróneo, indebido, que reclama ser superado. Esto es lo que llamo adversario, acantilado hostil que vemos elevarse actualmente sobre nuestro suelo, que, por tanto, surge también de éste y en contraste con el cual descubrimos la figura de nuestra doctrina. El adversario no es nunca inefectivo pasado: es siempre contemporáneo que nos parece una supervivencia"."

Lo que Parra tenía a la vista era la poesía de Neruda: una sensibilidad, un modo, una vigencia de lenguaje y visión. Representaba el "adversario" que nos explica el "anti" con que la poesía de Parra nace históricamente. Porque es en lucha contra ese fondo que Parra modela su "figura" espiritual. No se trata pues de una negación suicida, sino de un proceso de diferenciación y descubrimiento a partir de una resistencia. Lo que descubrió fue la "antipoesía", y ese descubrimiento lo salvó y salvó a la poesía chilena de la detención y la imitación retórica.

3 Solapa de Poemas y antipoemas, $2^{\text {a }}$ ed., Santiago de Chile, Editorial Nascimento, 1956.

4 Origen y epilogo de la filosofía. Obras Completas, Madrid, Revista de Occidente, 1962 (primera edición) T. IX, p. 395. 
Pero si bien la antipoesía vino para romper el cerco nerudiano, en último término tenemos que ver en ella un estilo gracias al cual se nos han revelado nuevos contenidos humanos y sociales. De otra manera, es obvio, no habría sobrevivido. Y esto Netuda lo comprende. Parra no es para él un contendor desaforado; lo entiende como un explorador que ha creado un sistema poético tan necesario y válido como el suyo, aunque enclavados en tiempo y circunstancias diferentes. Son además dos sistemas que en la comparación se definen mejor: a la luz del uno, el otro aprieta sus formas y así las aprehendemos más nítidamente.

Vamos en seguida a instalarnos detrás de la poesía de Neruda y de Patra, pero sin perderlas de vista, y a poner a estos dos escritores en un paralelo. Ciertos hechos y detalles que son parte de la biografía de cada uno, nos servirán, al contraponerlos, para ir desprendiendo actitudes, énfasis, tonalidades. La intención es construir un pequeño marco de observaciones, un conjunto de constancias que puedan funcionar a la vez como un poder auxiliar de comprensión y como un miradero.

Pablo Neruda es un hombre alto, grueso, de movimientos sin urgencia ni aspereza. Tiene un rostro oliváceo, oblongo, de piel ceñida; la nariz maciza, de fina línea; la frente limpia, espaciosa, curvada. Los ojos perezosos, encapotados, y la voz lenta, monótona, con resonancias de caverna o de salmodia, le dan un aire algo fabuloso, la aristocracia natural y lejana de los seres marinos.

Entre Neruda y el mar hay una afinidad irremediable. Desde Isla Negra, donde vive, escribió hace poco: "Durante grandes años compartí mi vida con el mar. No fui navegante, sino observador intransigente de las alternativas del océano. Me apasionaron las olas en sí mismas, me aterraron y me ensimismaron los voluntatiosos maremotos y marejadas del océano chileno. Me hice experto en cetáceos, en caracolas, en mareas, en zoofitos, en medusas, en peces de toda la pecería marina. Admiré la tridacna gigante, ostión devorador, y recogí en California los spondylus, góticos y nevados, o la oreja de mar que tiene todo el arco iris en su concha de nácar. Largo tiempo viví junto al mar en Ceylán, y saqué con los pescadores los elementos marinos más extraños y fosforescentes. Por último, me vine a vivir en la costa de mi patria, frente a las grandes espumas de Isla Negra. Aquí los inviernos transcurren con un espacio poblado hasta el infinito por el férreo mar y por las nubes que lo cubren. El mar me pareció más limpio que la tierra. No vemos en él los crímenes diabólicos de las grandes ciudades, ni la preparación del genocidio. A la orilla del mar no llega el smog pustulario, ni se acumula la 
ceniza de los cigarrillos difuntos. El mundo se oxigena junto a la higiene azul de las olas"."

Parra en cambio es un poeta de tierra adentro, mediterráneo y seco. De mediana estatura, camina con el reposo antiguo de un hombre de provincia. Su rostro no suscita el contexto de horizontes ilimitados ni desencadena ninguna imaginación marina; le recorta el vuelo a nuestra mirada que se queda en lo cercano: "una cabeza de enorme frente despejada y unas arrugas simiescas, cavadas sin duda desde la infancia, que le dan una mueca permanente de feroz alegría, los ojos intensos y algo fijos en los que también baila una risa, en la boca en cambio una son. risa triste, casi de dolor y tierna". "Habla con una voz de primer plano, clara, de relieves precisos y próximos. El rostro y la voz no nos sugieren el espacio dilatado sino la presencia del tiempo: nos comunican una historia más del hombre que de la naturaleza.

Contrariamente a Neruda, se ha ido a vivir en los faldeos de la Cordillera, de cara al smog de la ciudad de Santiago. Allí, en La Reina, "ha puesto una casa prefabricada, llena de libros, de sillas, de mesas y unas cuantas lámparas de dudoso funcionamiento. Hay cuadros en las paredes de rústica tabla; también hay un fonógrafo de cuerda y bocina, un guitarrón y un anafe. Por razones un tanto inexplicables, la casa no tenía aún ni agua ni luz eléctrica cuando lo visité"'."

El correlato de Neruda es el mar; el de Parra lo dan la Cordillera, atrás, y el espectáculo de la ciudad, delante. Entre estas dos realidades que son el equivalente geográfico de la frente y las arrugas de su cara, hay una sonrisa tierna prisionera en la boca: es un reducto de pureza que encuentra su medida en el perfume del aromo y en los colores de la mariposa:

La verdad es que me siento feliz

a la sombra de estos aromos en flor

hechos a la medida de mi cuerpo.

Extraordinariamente feliz

a la luz de estas mariposas fosforescentes

5 "Destrucciones en Cantalao". Revista Ercilla, Santiago, semana del 11 al 17 de marzo, 1970, p. 68.

- Emir Rodriguez Monegal, "Encuentos con Parra". Revista Número, Montevideo, Año 1, No 1, abril-junio de 1963, segunda época, p. 57.

7 Fernando Alegtia, "Nicanor Parra". Las fronteras del realismo. Santiago de Chile, Editorial Zig-Zag, 1962, p. 196. 
que parecen cortadas con tijeras

hechas a la medida de mi alma.

("Acta de Independencia", La camisa de fuerza)

En 1962 la Facultad de Filosofía y Educación de la Universidad de Chile recibió a Pablo Neruda como miembro honorario. Quien lee el dis. curso de recepción es Nicanor Parra. En el suyo, Neruda habla de dos escritores chilenos: el poeta Pedro Prado y el cuentista Mariano Latorre. Introduce recuerdos personales, experiencias de juventud; traza el itinerario de su pensamiento, poético y social; todo ello en un tono fraternal, amable, de equilibrio conmovido.

Parra presenta a Neruda, hace un análisis general de la obra, marca las etapas de evolución y la considera como la aventura de un hombre inteligente y sensible que busca su lugar en el mundo. Pero ante el género del discurso académico su actitud es por completo opuesta a la de Neruda. Este se sitúa en él tranquilamente, preocupado nada más que de llenarlo con las palabras y los pensamientos oportunos. En Parra sin embargo notamos que desde el comienzo se siente incómodo con las fórmulas y convenciones: "A decir verdad, el discurso académico es un género literario que se halla casi en contradicción con el temperamento fragmentario y díscolo del antipoeta". " Para salir del paso, adopta un punto de vista oblicuo: con un ojo examina seriamente el tema, cita poemas, establece relaciones y no deja lugar a dudas de que respeta $y$ admira la obra de Neruda; pero con el otro ojo, el del humor y el "anti", se retira y despega e interrumpe la exposición; abre paréntesis que van isonizando el género en que se expresa: se mete en él a la manera de un saboteador o, como él dice, de un "guerrillero". Neruda, en la lectura y en sus poemas, nos hace olvidar la forma, se sirve de ella solamente; Parra la destaca, llama nuestra atención sobre ella; frente a la gravedad serena del uno, la agresividad juguetona del otro.

Los títulos de los libros (para no hablar de los poemas) nos abocan también al punto de vista "ingenuo" de Neruda y al oblicuo de Parra. Los dos son diestros y exactos tituladores. Cuando leemos los títulos de Neruda: Tentativa del hombre infinito, Residencia en la tierra, Canto general, Odas elementales, sabemos que es el creador quien titula; cada título se adhiere a la respiración del poema y lo prologa. Pero los títulos

8 Discurso citado, p. 13. 
de Parra: Poemas y antipoemas, Versos de salón, La camisa de fuerza, Artefactos, nos ponen en otra perspectiva: son títulos acuñados por un creador y por un crítico; es decir, estos títulos contienen además un juicio sobre las obras, una elaboración intelectual que se agrega al acto creador.

Tal comprobación nos ayuda a resolver un problema más. Aparte noticias incidentales, biográficas, de poetas amigos y lecturas, de vicisitudes políticas y evocaciones de infancia, la doctrina estética de Neruda tenemos que construirla desde sus libros. Por supuesto, andaríamos descarriados si no hiciéramos otro tanto con Parra. Pero en el antipoeta nos topamos con un "más": la actividad del plano del juicio, inseparable de su creación, lo ha llevado a razonar lo creado en conferencias, entrevistas y poemas, dándole la beligerancia de una dimensión doctrinaria. En este sentido, Parra está en la tradición de Huidobro, el otro gran teorizador de su propia poesía. No es pues azaroso que sean los únicos poetas chilenos que han puesto sus creaciones bajo un signo de batalla: el "creacionismo" y la "antipoesía".

¿Y la política? En 1945 Pablo Neruda es elegido Senador de la República por las provincias de Tarapacá y Antofagasta, y ese mismo año entra al Partido Comunista de Chile. Cuando regresa de la noche, la desesperación y el caos de las Residencias, e inicia, alegre, seguro, renacido, la fase auroral del Canto general, lo hace de la mano del marxismo. En el proletario, como en la naturaleza y la historia de Hispanoamérica, ve los cimientos de futuras y transparentes arquitecturas humanas y sociales. La materia y el hombre guardan una promesa de redención.

A Parra le espantan las grandes armazones ideológicas (políticas o religiosas); le parecen una amenaza y una "camisa de fuerza"; no cree en ellas porque intuye que nuestro presente pide un receso y un olvido de las doctrinas para someternos a una revisión minuciosa y despiadada. No es el turno del proletario sino el del tábano socrático: "La antipoesía es una lucha libre con los elementos, el antipoeta se concede a sí mismo el derecho a decirlo todo, sin cuidarse para nada de las posibles consecuencias prácticas que puedan acarrearle sus formulaciones teóricas. Resultado: el antipoeta es declarado persona no grata".?

Parra causa desazón en los "afiliados": aunque no consiguen encasillarlo, sospechan que en su posición no hay frivolidad; se declara "izquierdista no militante". En 1969 un redactor (Julio Huasi) de la revista

- Discurso citado, p. 13. 
chilena Punto final le hizo una entrevista después de haber ganado el Premio Nacional de Literatura. El entrevistador disimula apenas la molestia ante las respuestas. "Yo relativizo todo, hasta la revolución", afirma Parra. Le pregunta si hay o no que hacerla: "Sí, pero racionalmente". ¿Y en qué consiste esa racionalidad de la revolución? Parra entrega una respuesta esquinada: "Yo no patrocino la vía violenta, aunque me la explico". El entrevistador le recuerda que lo acusan por no tomar partido, políticamente, en las luchas sociales. La respuesta ahora va sin ambigüedades, definitiva: "Es que yo no soy un político ni un predicador. No soy un sujeto al estilo lírico, me considero simplemente un medium. Me han acusado de cometer diversos crímenes en mis relaciones poéticas con instituciones oficiales y no oficiales norteamericanas y los pienso seguir cometiendo". ${ }^{10} \mathrm{Ha}$ ido invitado a los Estados Unidos, pero también a Rusia, China Comunista y Cuba. Y no se opone a que Punto final, una revista política de extrema izquierda, publique un grupo de poemas inéditos suyos.

Es un hombre tras la verdad y no alguien ya en posesión de ella. La realidad le parece sospechosa, y los valores burgueses y las instituciones (el matrimonio, los Partidos Políticos, la Iglesia), desfinanciados, en quiebra. Y como no es "un sujeto al estilo lírico", sino un moralista igual que Quevedo, una conciencia ética que se siente traicionada por el medio, adopta el punto de vista irónico, oblicuo, y se proclama un "medium": un develador irreductible a la miseria de las verdades aparentes. La Iglesia Católica y los Estados Unidos, dos organizaciones de pensamiento que representan el orden social y moral de lo establecido, le son extraños, le inspitan recelo, y mezclando la broma a la seriedad se declara "país independiente" de la Iglesia, y frente a los Estados Unidos sostiene su identidad personal, que es por otra parte la de Hispanoamérica. En el poema "Acta de Independencia" dice:

Independientemente de los designios de la Iglesia Católica me declaro país independiente.

A los cuarentaynueve años de edad un ciudadano tiene perfecto derecho a rebelarse contra la Iglesia Católica.

(La camisa de fuerza)

\footnotetext{
10 "El antipoeta y las propinas". Punto final. Santiago de Chile, Año IV. 14 de octubre de 1969 , No 89 , pp. 12-13.
} 
$Y$ en "Ponchartrain Causeaway":

Perdón

lo siento muchísimo

no tengo nada que hacer con estos puentes inolvidables

reconozco que son largos

¿infinitos?

O.K.: Infinitos

pero no es mucho lo que tengo que hacer yo con estos crepúsculos

[maravillosos

gracias por los sánguches y las cocacolas

gracias por las buenas intenciones

y también por las malas

mi estómago está de fiesta

¿oyen la sonajera de tripas?

Mientras no se demuestre lo contrario

seguiré llamándome como me llamo.

(Otros poemas)

2

¿A qué paisaje pertenecen estos dos poetas, Neruda y Parra? ¿De qué zona geográfica de Chile han salido? Parra es de Chillán, una ciudad que cierra por el sur la zona central del país, la más vieja, la que primero colonizaron y cultivaron los españoles. Su organización socioeconómica y la mentalidad adherida a ella y al trasfondo de la naturaleza, han sido el fundamento histórico de la vida nacional. Muchos rasgos de la psicología del chileno, de su peculiar manera de tratar con la realidad, están ya en el "huaso", el tipo campesino que la habita, y en el folklore y la poesía popular. Las ciudades, abiertas al exterior, no son otra cosa que expresiones de la existencia rural, en un sentido económico y cultural. El límite norte de la zona central es Santiago. Los alrededores de ambos extremos tienen prestigio como condensaciones folklóricas importantes. Quinchamalí, cerca de Chillán, y Pomaire, próximo a Santiago, son concentraciones de cerámica.

Es éste un paisaje cultivado, de contrastes y perfiles claros. Las estaciones del año no son abstracciones de calendario; se suceden a paso lento, bien diferencindas. Entre la Cordillera de los Andes, coronada de 
nieve y luz, y la de la Costa, más baja y oscura, hay valles, planicies, cerros menores. Ríos que en el invierno se desbocan inundando y destruyendo caminos, puentes, líneas férreas, mientras en el verano languidecen, mezquinos, en un cauce pedregoso que les queda grande. A la destrucción de los ríos colaboran los terremotos periódicos que borran ciudades y alteran la geografía. Psicológicamente, el chileno se "salva" con una respuesta compleja: en la destrucción de la naturaleza contempla su propio desastre, anticipa en la vivencia su muerte, y la acepta. La aceptación lo cura en salud y le crea una actitud cautelosa, reservada y práctica ante las cosas (sabe que son provisionales, carne de muerte), y lo arma con un humor sano, socarrón, corrosivo, enemigo de posturas enfáticas, absolutas, y atento a sorprender en los gestos grandilocuentes el lado ridículo o falso para desinflarlos. Este es el humor de Parra. En él pueden convivit lo puro y lo macabro, la ingenuidad y la ironía, la defensa y la agresión dentro de la mesura.

En el paisaje de la zona central la mirada nunca se pierde en horizontes de desvario; pronto la detienen, la orientan y estabilizan la proximidad del cerro, de las viñas, el huerto, las alamedas, los retazos de trigo y arroz. La luz del cielo (es decir, la pupila que la mira) tiene antigüedad; es delgada y doméstica. Por la noche, el silencio no nos hunde en espacios sin fondo, de vértigo; es un umbral que el oído y la imaginación pueblan con personas, cosas y ruidos ausentes, pero que con el día recuperamos. Predomina el arcaísmo en la naturaleza, el lenguaje, las costumbres y la música. Las cosas nos hablan de un tiempo humano trabajado, consistente; más allá de ellas hay otros hombres, otros momentos, y ante esta evidencia la conciencia se esponja, tranquila. En el paisaje del Chile central y en la poesía de Nicanor Parra impera una misma ley: la ley de lo próximo, de los objetos claros y distintos. ${ }^{11}$

Pablo Neruda es de Temuco, una ciudad de frontera: ahí empieza el sur y un paisaje de otra fisonomía. Desde la época de los españoles hubo por supuesto poblaciones. Pero en general ha sido una región poblada y cultivada tardíamente. Fue durante la República, en el siglo pasado y a comienzos del actual, que se desarrollaron programas oficiales de colonización. De Chillán y otras ciudades del centro salieron familias de colonos y de Europa vino la inmigración alemana. También a fines del siglo pasado el Gobierno tuvo que enviar un ejército para ter-

11 Un buen análisis de la "proximidad" en el paisaje y en la poesia de Parra es el de Pablo Garcia, "Contrafigura de Nicanor Parra". Atenea, Año XXXII, Tomo CXIX, Núms. 355-356, 1956, p. 153. 
minar de pacificar a los araucanos, los héroes de Ercilla, huraños y rebeldes todavía.

La lluvia lenta, fría, inacabable (ese ámbito de resonancia asordinada de la infancia de Neruda), tiene su domicilio en el sur. La lluvia y las raíces, la sexualidad acuciosa de la naturaleza. Anchos y morosos rios, lagos somnolientos y distantes, el verde uniforme, la humedad incursionando en las habitaciones de madera, en la ropa. La tierra padece de una avidez de agua insaciable: absorbe los diluvios con una rapidez asombrosa. $Y$ cuando por fin llega el verano, siempre breve, un par de meses llenos de excepciones, la tierra y el aire se transfiguran: son realidades nuevas, nacientes, originarias; el cielo, salido de las aguas, florece en una luz cegadora, de una vitalidad y belleza vegetales: es la misma luz que baña los objetos en las Odas elementales. Y por la noche, el silencio: un silencio que despierta en nosotros presencias cósmicas y genésicas; adivinamos el movimiento abismal de los astros y, a ras de tierra, el de los caracoles que se deslizan mudos sobre la hierba húmeda, ciegos peregrinos de la materia.

La poesía de Neruda cuenta con la actividad de las raíces, la distancia, la mitología de la madera y las leyendas del agua, con la luz vegetal y los renacimientos. En ningún otro poeta chileno son más hondos y constantes los ocultos lazos entre la poesía y la magia, entre la imagen poética y la metáfora mítica, entre el verso y la frase ritual. Cuando los objetos entran en contacto con su palabra, caen en el acto en el centro vivo de una alquimia. Cada poema suyo es el marco de una metamorfosis. Porque el instinto poético de Neruda, su método, se aplica meticulosamente a descubrir en las cosas la dormida raíz del mito: cuando la despierta, un nuevo ser ha nacido. Fresco, emergente, material, tocado por la gracia: las Odas elementales. O sombrio, siniestro, caótico, tocado por la muerte y la disolución: Residencia en la tierra.

Demos un ejemplo de cumplimiento del método, el poema "Pequeña América":

\author{
Cuando miro la forma \\ de América en el mapa, \\ amor, a ti te veo: \\ las alturas del cobre en tu cabeza, \\ tus pechos, trigo y nieve, \\ tu cintura delgada, \\ veloces ríos que palpitan, dulces \\ colinas y praderas
}


y en el frío del sur tus pies terminan su geografía de oro duplicado.

Amor, cuando te toco no sólo han recorrido mis manos tu delicia, sino ramas y tierra, frutas y agua, la primavera que amo,

la luna del desierto, el pecho de la paloma salvaje, la suavidad de las piedras gastadas por las aguas del mar o de los ríos y la espesura roja del matorral en donde la sed y el hambre acechan.

$\mathrm{Y}$ asi mi patria extensa me recibe, pequeña América, en tu cuerpo.

Aún más, cuando te veo recostada veo en tu piel, en tu color de avena, la nacionalidad de mi cariño.

Porque desde tus hombros el cortador de caña de Cuba abrasadora me mira, lleno de sudor oscuro, y desde tu garganta pescadores que tiemblan en las húmedas casas de la orilla me cantan su secreto.

$\mathrm{Y}$ así a lo largo de tu cuerpo, pequeña América adorada, las tierras y los pueblos interrumpen mis besos y tu belleza entonces no sólo enciende el fuego que arde sin consumirse entre nosotros, sino que con tu amor me está llamando 
y a través de tu vida

me está dando la vida que me falta

y al sabor de tu amor se agrega el barro,

el beso de la tierra que me aguarda.

("Pequeña América", Versos del Capitán)

En la poesía en lengua castellana, sólo San Juan de la Cruz y Góngora se le asemejan. Pero San Juan trasciende lo real movido por un impulso místico ascensional, por una "llama" de amor divino, y el len. guaje del amor humano, los elementos de la naturaleza, no son sino "figuraciones de la divinidad" (Vossler), mientras Neruda, poeta del amor humano, dionisiaco y vegetal, "místico" de la materia, se queda definitivamente en la tierra. Y si Góngora se refugia en la mitología clásica para promover sus cultas metamorfosis, Neruda trabaja imitando las metamorfosis de la naturaleza americana.

El pocta chileno participa de un destino adánico: le ha sido otorgado el privilegio de la nominación. Nombrar significa delinear un rostro en la materia anónima, dotar de un ser a las cosas $y$, así, revelarlas. La revelación es un abrir y un aparecer asombrado, virginal. Es también una posesión: un acto de incorporación del ser nominado al reino de 10 humano, a una cultura. Desde este punto de vista, Cristóbal Colón fue nuestro nominador primero. En el Primer Viaje lo tenemos ocupado nombrando islas, ríos, cerros, países. Al nombrar lo americano, con un recogimiento casi religioso que nos conmueve y sin que la palabra "maravilla" se le suelte de los labios, lo saca de su anonimato, quiebra el círculo mítico de las repeticiones y analogías y lo abre a la historia de la cultura occidental. Desde entonces la empresa de la literatura hispanoamericana no ha sido otra que la de nombrar y renombrar la realidad para, en el interior de la cultura a la que fuimos incorporados, definirla, tallarle un rostro original, procurando no perder ninguna de las sustancias nativas, de la naturaleza y las culturas autóctonas. Neruda es un hito monumental en ese proceso.

No olvidemos que Neruda comenzó por nombrarse a sí mismo, mudando su nombre anterior, Neftalí Reyes, por un bello pseudónimo: "Pablo Neruda". Podemos entender los pseudónimos desde una perspectiva doble. Como una negación soberbia del nombre originario. $Y$ en segundo lugar, como una forma que atribuye una nueva identidad a la realidad primera. En este último caso, el de Neruda, el pseudónimo 
oculta para revelar mejor lo ocultado; ni mordaza ni represión, sino una metáfora que a través del nombre creado ("Pablo Neruda") revela la esencia del nombre real (Neftalí Reyes). En otras palabras: la realidad primera ha sido reelaborada por la metáfora en una segunda realidad o superrealidad.

Recordemos el poema citado y ordenemos una rápida serie para poner en ella la cuestión del pseudónimo. Así como los pechos de la mujer se han metamorfoseado en "trigo y nieve", la delgada cintura en "veloces ríos que palpitan" y la garganta en "pescadores que tiemblan en las húmedas casas de la otilla", sin que haya negación sino transformación en virtud de la metáfora, así Neftalí Reyes se ha metamorfoseado en "Pablo Neruda". Y ya sabemos desde Vico que la metáfora es un pequeño mito. Neruda es pues en sí una metáfora, todo un mito poético. En 1946 los Tribunales chilenos le dieton existencia oficial al mito, declarando que el nombre legal del poeta sería "Pablo Neruda".

¿Qué pasa en cada metamorfosis? Ocurre el nacimiento de un ser. Mejor aún: ocurre una fundación. En la delgada cintura de la mujer el poeta funda unos "veloces ríos que palpitan". Nuestra imaginación se nos va prendida al movimiento nuevo y sensual del mito fundado; la dinámica de esos ríos nos aleja: la "delgada cintura" ha quedado atrás, en silencio, distanciada, en reposo feliz de parturienta.

Las metamorfosis no se celebran frente a la mirada desnuda; exigen el velo y la distancia. Como en los ritos de las sociedades primitivas: los sacerdotes, oficiantes de la divinidad, se enmascaran, y una de las funciones de la máscara es aislar al enmascarado, retirarlo de los demás, generando entre él y el resto una zona neutral, propicia para que los poderes sagrados se manifiesten. Y tampoco los "poderes" poéticos de Neruda se manifiestan sin la mediatización del velo; la función distanciadora de la máscara la realizan aqui el ritmo y el tono: lentos, de amplias pausas uniformes, graves, rituales. También las metamorfosis de Góngora buscaban los escenarios remotos: las orillas del Nilo, una Sicilia fabulosa.

Si en Neruda hay una vocación épica en la medida en que al nombrar afirma y constituye, la vocación de Nicanor Parra es trágica porque al nombrar niega y desintegra. Neruda es un "héroe" y Parra un "mártir". Para aquél la realidad es una cantera con cuyos materiales levanta inéditas construcciones. La misión de Parra es dolorosa: de zapa y demolición. Allí donde el uno funda una presencia, el otro funda un vacío: una ausencia de sentido. Reemplaza el ritmo ceremonial por el sarcasmo y la mueca y el velo estético del pseudónimo por la realidad desencu- 
bierta de su propio nombre: "Nicanor", un nombre común, áspero y "antipoético".

Es también un nominador, pero un nominador al revés. Dice en "Advertencia al lector":

Conforme: os invito a quemar vuestras naves, como los fenicios pretendo formarme mi propio alfabeto.

(Poemas y antipoemas)

¿Para qué el nuevo alfabeto, el nuevo lenguaje? La invitación al lector es inequívoca: para "quemar vuestras naves". Las "naves" son el lenguaje convencional en que se expresa una realidad asimismo convencional. Es decir, Parra pretende formarse su propio lenguaje para promover un incendio. Frente al nuevo lenguaje, como frente a un detector de mentiras, la realidad debe contemplarse y ver qué fea y falsa es. He aquí una muestra de este método, el poema "Oda a unas palomas":

Qué divertidas son estas palomas que se burlan de todo, con sus pequeñas plumas de colores $\mathrm{y}$ sus enormes vientres redondos.

Pasan del comedor a la cocina como hojas que dispersa el otoño $y$ en el jardín se instalan a comer moscas, de todo un poco, picotean las piedras amarillas o se paran en el lomo del toro: más ridículas son que una escopeta o que una rosa llena de piojos.

Sus estudiados vuelos, sin embargo, hipnotizan a mancos y cojos que creen ver en ellas la explicación de este mundo y el otro.

Aunque no hay que confiarse porque tienen el olfato del zorro, la inteligencia fría del reptil y la experiencia larga del loro. 
Más hipócritas son que el profesor
y que el abad que se cae de gordo.
Pero al menor descuido se abalanzan
como bomberos locos,
entran por la ventana al edificio
y se apoderan de la caja de fondos.

(Poemas $y$ antipoemas)

Estamos lejos de Ios espacios abiertos y dilatados. El lugar de la naturaleza lo ocupa ahora la ciudad, y a lo distante sucede lo próximo. La mirada se retrae y palpa, con disgusto, la grisura de los objetos cuotidianos, domésticos, huérfanos de prestigio, circundados por la luz y el aire impuros de las calles. Parra los observa con calma, desconfiado, resuelto a no dejarse engañar.

La convención asocia las palomas a lo manso y suave; son seres femeninos, sensuales. Parra no está dispuesto a sumarse a ningún lugar común sin previo examen. Espía las palomas y luego, detrás de las apariencias, en el fondo mismo de la convención (lenguaje y realidad), halla el nido de una superchería y nos comunica su testimonio. Contra. riamente a lo que se cree, nos dice, las palomas no son hermosas ni perfectas sino "ridiculas" y sucias (comen moscas), y sus movimientos no tienen nada de espontáneos: ellas los ejecutan para tejer una pantalla de humo que despiste a los espectadores y oculte sus intenciones: apoderarse de la "caja de fondos". Son pues "hipócritas", tienen "el olfato del zorro, la inteligencia fría del reptil y la experiencia larga del loro".

El poema desmitifica a las palomas; el ácido que contiene el lenguaje "antipoético" les disuelve la apariencia y les desnuda su verdadera esencia: la impostura. La poesía de Parra está atestada de impostores desenmascarados: piénsese, por ejemplo, en el poema "El túnel" o en "La víbora". Pero la esencia de las palomas es también la de la sociedad burguesa en que vivimos, porque las palomas son un símbolo. Ellas, el mundo que simbolizan, se han convertido en nuestros enemigos: nos engañan, nos roban; son, en el más profundo sentido, antisociales, puesto que traicionan el ser social del hombre y le escamotean la verdad (su "caja de fondos"). La sociedad actual, iluminada por el símbolo, tiene como base una anomalía: la contradicción entre el ser y el parecer, entre la forma y el contenido, entre la convención y la verdad. 
Parra termina su poema con un llamado:
A ver si alguna vez
nos agrupamos todos
y nos ponemos firmes
como gallina que defiende sus pollos.

Al asalto de las palomas hay que responder con una defensa y a la vacuidad del mundo con una esperanza. Aunque esa posición nos precipite en la angustia, en la soledad, sólo manteniendo los ojos abiertos a los "estudiados vuelos" de las palomas podremos "alguna vez" derrotar la anomalía. Debemos defendernos del disfraz seductor de las palomas que hipnotizan a "mancos y cojos", o sea, a los incautos, a los que se entregan como prostitutas al relumbrón de la sociedad burguesa, a sus pseudovalores y pseudoconquistas. Los "mancos y cojos" piensan, de buena o mala $\mathrm{fe}$, que las palomas son palomas y que nuestro mundo es una rosa. Pero cuidado, advierte Parra: la rosa está "llena de piojos". La realidad no tiene fondo, y el que se nos propone como tal, es la boca de un abismo, al que nos asoma la poesía de Parra. Las palomas son indignas de un encomio y el tiempo de las odas se ha ido. Por eso, para decirlo, Parra escribe una anti-oda: desaloja la alabanza y el entusiasmo y en su sitio instala, mordiente, la ironía, un taller de denuncias.

$Y$ si ya no podemos escribir odas, porque su espíritu se sostendría en el vacío, gratuitamente, sin justificación histórica, tampoco tiene justificación la existencia de poetas serenos, dueños de sí, olímpicos. En su "Manifiesto" anuncia:

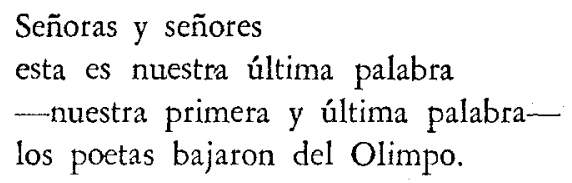

(Otros poemas)

Después de Neruda sólo podía venir Parra en la poesía chilena. La historia de la poesía, y de una cultura, no es jamás una línea recta de progresión uniforme (esa fue una de las ilusiones del positivismo decimonónico y de su fe en el "progreso"). Por el contratio, avanza al ritmo de construcciones y destrucciones, de afirmaciones y negaciones que a su vez preparan el camino a afirmaciones venideras. El ciclo de Neruda 
fue fundacional. El de Parra nos ha dejado el campo visual cubierto de ruinas y escombros, despejado. Sin estas demoliciones, la nueva poesía chilena e hispanoamericana no habría podido contar con una realidad y un lenguaje desmitificados para continuar el proceso. Neruda, siempre lúcido, comprendió muy bien la inevitabilidad del cambio. Al finalizar su discurso académico de 1962 dijo: "Mi canto no termina. Otros renovarán la forma y el sentido. Temblarán los libros en los anaqueles y nuevas palabras insólitas, nuevos signos y nuevos sellos sacudirán las puertas de la poesía. Aqui mismo y hace escasos minutos, me ha conmovido una vez más la desbordante vocación, la prodigiosa invención con que Nicanor Parra consteló generosamente esta sala y encendió una fosfórica luz sobre mi cabeza provinciana". ${ }^{12}$

LeÓNidAs Morales TORo

University of California,

Los Angeles.

12 "Mariano Latorre, Pedro Prado y mi propia sombra". Discursos, p. 87 y s. 
